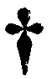 \\ Georg Gaffky
}

Vor 8 Jahren widmete Gaffky im 66 . Band dieser Zeitschrift seinem dahingeschiedenen verehrten Lehrer und Freunde, dem Mitbegründer der Zeitschrift, herzliche Worte der Trater. Und nun ist nach einer so kurzen Zeitspanne dem unvergeblichen Meister sein treuester Schüler in den Tod gefolgt!

Gaffky hat sich seit dem .Jahre 1905, wo er die Leitung des Instituits für Infektionskrankheiten übernahm, an der Schriftleitung dieser Zeitschrift beteiligt; seit 1912, wo er die amtliche Tätigkeit aufgab und seinen Wohnsitz nach seiner Vaterstadt Hannover verlegte, hat er fast damernd die Geschäfte der Schriftleitung geführt. Die Autoren der Zeitschrift haben in ihm stets einen gerechten nnd wohlwollenden Beurteiler der eingesandten Arbeiten gefunden; die Verlagsbuchhandlung wurde von ihm bei der Herstellung und Ausgabe der Hefte durch seine vorbildliche Geschäftsführung wirksam unterstützt; den Kollegen der Schriftleitung war er ein erfahrungsreicher und besonders bei den nicht immer vermeidlichen Konflikten mit Autoren und in Fragen des Takts stets verläßlicher Berater.

Auch die mancherlei neue 'Tätigkeit, zu der ihn der Krieg berief, hinderte ihn nicht, die Schriftleitung nach wie vor mit unermïdlichem Kifer zu erledigen. - Oft streiften seine 
ges bäftlichen Briefe atus der letaten 7eit die militärische und polivische Lage, immer hoffinungsfroh und voll unbedingten Vertrauens auf unser Heer und Volk. Ein gütiges Geschick hat ihm die Erkenntnis erspart, dah all unserem Ringen der erhoffte Erfolg trotzdem versagt geblieben ist; eine Enttäuschung, die gerade er ungemein schwer verwunden haben würde.

Wir werden seiner über das Grab hinaus in aufrichtigster Verehrung und herzlicher Dankbarkeit gedenken.

\section{Die Schriftleitung.}

C. Flügge. F. Nenfeld.
Die Verlagsbuchhandlung.

r. Halem. Thesing. 